1 Universidade Federal do Sul da Bahia (UFSB), Centro de Formação em Ciências da Saúde (CFS)

- Teixeira de Freitas (BA), Brasil.

silier@outlook.com

2 Universidade Federal da Bahia (UFBA), Instituto de Saúde Coletiva (ISC) Salvador (BA), Brasil.

lirangel@ufba.br

3 Universidade Federal da Bahia (UFBA), Escola de Enfermagem - Salvador (BA), Brasil.

priscillaporto@outlook.com

\section{Discurso Jurídico-Moral Humanizador sobre drogas e violência sanitária na saúde da família}

\author{
Humanized Moral-Legal Discourse on drugs and healthcare violence \\ in family health
}

Silier Andrade Cardoso Borges ${ }^{\mathbf{1}}$, Maria Ligia Rangel Santos², Priscilla Nunes Porto ${ }^{\mathbf{3}}$

DOI: 10.1590/0103-1104201811707

RESUMO As mídias influenciam os sentidos entre profissionais e usuários, que podem coadunar com práticas assistenciais que reiteram o modelo manicomial. Por meio da análise de entrevistas realizadas com profissionais da Atenção Primária à Saúde, utilizando-se como material de apoio as notícias sobre o programa Crack, é Possível Vencer publicadas em jornais impressos, observou-se a emergência de uma formação discursiva Jurídico-Moral 'Humanizadora', sistema simbólico compartilhado pelos profissionais que rejeita em sua superfície a intervenção policial e carcerária para substituí-la pela violência sanitária, sustentando a internação compulsória diante da falência do convencimento.

PALAVRAS-CHAVE Cocaína crack. Atenção Primária à Saúde. Comunicação em saúde.

ABSTRACT The media influences the meanings among professionals and users, which can conjugate to social welfare practices that reaffirm the asylum model. By means of analysis of interviews performed with professionals of Primary Health Care, using as support material the news items on the program Crack, it is Possible to Overcome published in the printed press, it was observed the emergence of a 'Humanizing' Legal-Moral Discursive Formation, a symbolic system shared by professionals, that rejects, on its surface, the police and correctional interventions, replacing these with healthcare violence, supporting compulsory committal in view of the failure of persuasion.

KEYWORDS Crack cocaine. Primary Health Care. Health communication. 


\section{Introdução}

O programa Crack, é Possível Vencer, coordenado pelo Ministério da Justiça em parceria com os demais ministérios, objetiva prevenir o uso de crack e promover a atenção ao usuário dessa substância ilícita por meio de estratégias que incluem serviços de tratamento e o enfrentamento ao tráfico de drogas, mediante ações que envolvam informação e capacitação'.

Os eixos de atuação do programa são prevenção, cuidado e autoridade. O eixo prevenção se dedica às ações que fortaleçam vínculos familiares e comunitários; é centrado em ações de educação permanente de profissionais da rede intersetorial para atuarem na prevenção do uso do crack, álcool e outras drogas. O eixo cuidado orienta o desenvolvimento de ações para estruturar redes de atenção à saúde e assistência social para atendimento aos usuários de drogas e seus familiares. No eixo autoridade, o programa visa tornar mais resolutivo o enfrentamento à violência, por meio de recursos investidos em videomonitoramento, policiamento e bases móveis de segurança².

O Brasil é orientado por um modelo misto de atenção aos usuários de drogas. As políticas públicas brasileiras sobre drogas resultam de tensionamentos que envolvem, de um lado, instituições de caráter asilar e religioso que exercem segregação e, de outro, práticas que objetivam a reinserção social dos usuários de crack, centrados em serviços territoriais, orientados pela redução de danos e articulados em rede de serviços ${ }^{3}$.

Esses tensionamentos políticos e ideológicos se expressam por meio da ambiguidade constitutiva dos marcos regulatórios que versam sobre o consumo, a circulação e a assistência no País. De um lado, destacam-se a Lei ${ }^{0} 10.216 / 2001^{4}$, que institui a política de saúde mental, e a Política do Ministério da Saúde para Atenção Integral a Usuários de Álcool e Outras Drogas ${ }^{5}$, orientadas pela promoção da saúde e pela garantia de direitos dos usuários. De outro, a Política Nacional sobre Drogas (PNAD) e a Lei ${ }^{0} 11.343 / 2006$, conhecida como Lei de Drogas 6 , assim como o Decreto $n^{\circ} 7.179 / 2010$, que implementa o Plano Integrado de Enfrentamento ao Crack e outras Drogas 7 , abrindo caminho ao programa Crack, é Possível Vencer por meio da repressão do consumo e do consumidor.

Trata-se de um verdadeiro descompasso entre as políticas públicas sobre drogas nos campos da segurança e da saúde pública ${ }^{8,9}, 0$ que revela o quanto o percurso histórico das políticas sobre drogas no Brasil se relaciona com os aspectos econômicos, políticos e valorativos da sociedade, influenciando a formulação das normativas ${ }^{10}$. Tais disputas se expressam no cotidiano dos serviços por meio da precarização no processo de implementação da política de redução de danos, enquanto as comunidades terapêuticas, instituições privadas com fins lucrativos, são fortalecidas por meio de financiamento público, amparando-se na lógica da abstinência e da internação, guiadas pela política do medo desencadeada pela midiatização do rrack $^{\mathbf{1 1}}$.

Nesse sentido, a repressão estatal ao uso de drogas em espaços públicos, o uso de crack em cenas abertas, a situação de marginalização e o estigma vivenciado pelos usuários ampliam a condição de exclusão, por meio de sua (des)inserção nas políticas de seguridade social do Estado ${ }^{12}$.

A expressiva destinação de recursos para o programa Crack, é Possível Vencer tem adquirido visibilidade por meio das 'cracolândias', cenas de uso que mobilizam a atenção e a indignação da mídia e de setores da sociedade que exercem pressão sobre o poder público por soluções imediatas ${ }^{13}$. Dessa maneira, desafiam-se os modelos de atenção aos usuários de substâncias psicoativas por intermédio do sistema de saúde, substituindo-os por políticas de segurança pautadas na 'guerra às drogas', que pressupõem a criminalização do consumo e o encarceramento do consumidor.

Os meios de comunicação têm impacto sobre os papéis sociais na interação, 
afetando o modo que as pessoas se comunicam e agem ${ }^{14}$. A mídia, portanto, é agente de mudança social, sendo a midiatização um conceito-chave para compreensão desse fenômeno indissociável de instituições como família, religião, trabalho e política.

Ao considerar que as mídias afetam as práticas sociais, interferindo sobre outros campos e interações ${ }^{15,16}$, os discursos que associam a droga à morte e à periculosidade podem se distanciar da realidade concreta dos usuários e coadunar com práticas assistenciais na atenção primária que reiteram o modelo manicomial de atenção.

Esta pesquisa se dedica a analisar os modos de apropriação dos quadros discursivos da mídia sobre o programa Crack, é Possível Vencer pelos profissionais de uma Equipe de Saúde da Família (EqSF), discutindo a relação entre mídia e violência sanitária nos discursos e nas práticas assistenciais aos usuários de drogas exercidas pelos profissionais da EqSF.

\section{Métodos}

Este artigo é produto de pesquisa qualitativa e exploratória que consistiu em três etapas: seleção das notícias, análise de enquadramento e entrevistas de profundidade, em que se apresentam os resultados da terceira etapa.

Na primeira etapa, foram selecionadas 13 notícias sobre o programa Crack, é Possível Vencer veiculadas entre dezembro de 2011 e dezembro de 2014 pelos dois jornais de maior circulação do estado da Bahia.

A segunda etapa consistiu na análise dos dados mediante o modelo de Análise do Enquadramento, referencial teórico-metodológico promissor em estudos do campo da comunicação e saúde. Por meio da identificação de palavras e expressões recorrentes, debruçou-se à investigação dos quadros de referência de caráter simbólico e interpretativo que participam da construção das notícias em espaços de disputa de sentidos ${ }^{17,18}$.

$\mathrm{Na}$ terceira etapa, foram realizadas entrevistas de profundidade com 13 profissionais que atuam em uma Unidade de Saúde da Família (USF), tomando-se como material de apoio nas entrevistas as referidas notícias selecionadas na primeira etapa.

A pesquisa foi realizada com os profissionais de ensino superior, fundamental, médio e técnico vinculados a uma USF do município de Camaçari, estado da Bahia. Foram convidados os sujeitos que cumprissem o seguinte critério de inclusão: ser profissional vinculado ao serviço de saúde da USF. Entre os 6 profissionais de nível superior, foram entrevistados 1 enfermeira, 1 médico, 3 odontólogas e 1 gerente. Entre as 7 profissionais de ensino fundamental, médio e técnico, foram entrevistadas 4 agentes comunitárias de saúde, 1 técnica de enfermagem, 1 auxiliar de saúde bucal e 1 recepcionista.

As entrevistas foram orientadas por um questionário semiestruturado sobre a formação e a trajetória profissional na USF, bem como outros contextos profissionais, organizado em três tópicos: assistência ao usuário de crack; o programa Crack, é Possível Vencer; as interpretações dos profissionais entrevistados sobre as notícias apresentadas pelos jornais impressos referentes ao programa de enfrentamento ao crack.

As análises das entrevistas foram realizadas de acordo com os pressupostos teóricos e metodológicos da Análise do Discurso (AD), na perspectiva de Orlandi' ${ }^{19}$.

A análise foi realizada por meio da constituição de um 'corpus discursivo', composto por sequências extraídas dos recortes dos discursos dos profissionais que integram a EqSF. Os recortes foram realizados tomando por base a transcrição das entrevistas, conjunto de textos que formam o 'corpus empírico’, considerando suas condições de produção, os objetivos, os elementos teóricos e metodológicos desta pesquisa. Esse processo analítico de identificação das regularidades possibilita a identificação da Formação Discursiva (FD), em que se inscreve o que o sujeito diz, produzindo sentidos ${ }^{19}$. 
Foram mobilizados conceitos como exclusão, humanização, racionalidade, midiatização e violência sanitária, de modo a considerar a heterogeneidade das práticas discursivas que constituem um sistema simbólico e ideológico de diagnose e de intervenção terapêutica que estrutura os saberes profissionais da EqSF na assistência aos usuários de crack.

Todos os preceitos éticos foram respeitados. A pesquisa foi aprovada pelo Comitê de Ética em Pesquisa (CEP) do Instituto de Saúde Coletiva da Universidade Federal da Bahia (ISC UFBA) por meio do parecer $\mathrm{n}^{0} 1.778 .709$.

\section{Resultados e discussão}

\section{Discursos sobre drogas: multiplicida- des de sentidos}

Bravo $^{20}$ identificou em sua pesquisa dois discursos contrapostos que versam sobre o consumo de drogas: o discurso dominante e tradicional, centrado na abstinência e na estigmatização dos usuários, e o discurso de resistência ao dominante, mais recente, denominado redução de danos, centrado na cidadania e na reinserção, visando minimizar as consequências do consumo e incorporando a perspectiva do usuário no planejamento das ações.

A etapa da análise do enquadramento das notícias sobre o programa Crack, é Possível Vencer possibilitou elucidar a diversidade de perspectivas sobre ele, evidenciando uma polifonia de sentidos que não se reduziram ao binarismo de um discurso hegemônico em oposição a um discurso minoritário e contra-hegemônico.

Embora houvesse predominância do enquadramento Jurídico-Moral, foi possível constatar também, nas notícias selecionadas, a presença dos quadros Política de Saúde, em consonância com a concepção de drogas como problema de saúde coletiva, a ser enfrentado pelo usuário e pelos profissionais articulados à rede de atenção psicossocial e comunitária; o quadro Político-Econômico, que considera o crack como objeto de intervenção política por meio da captação e destinação de recursos públicos; e o quadro Biomédico, minoritário entre os demais, que considera o uso do crack como doença, e o usuário como indivíduo avolitivo, objeto do saber e poder médico.

Essas notícias selecionadas foram utilizadas durante as entrevistas, possibilitando observar que as interpretações dos profissionais da equipe de saúde da família não são redutíveis a posições dicotômicas, mas apresentam diversidade de sentidos, produzindo efeitos de desassistência aos usuários de crack.

\section{O Discurso Jurídico-Moral 'Humanizador'}

A análise das entrevistas possibilitou identificar, nos discursos dos profissionais, os efeitos de sentido e das condições de produção do discurso que remetem a uma FD, que foi definida como Discurso Jurídico-Moral 'Humanizador'.

Uma FD determina o que pode e deve ser dito em uma dada conjuntura sócio-histórica, considerando a posição ocupada pelo sujeito nessa conjuntura. Por meio da ideologia, apaga-se na formação discursiva a sua rede de relações, tornando opacos os seus modos de funcionamento ${ }^{19}$.

O Discurso Jurídico-Moral Humanizador consiste em um modelo híbrido de representação sobre os modos e as consequências de uso, as cenas de uso, as representações sobre o usuário (seus modos distintos de levar a vida, sobre o domínio de si e sobre o cuidado de si) e sobre a assistência profissional diante do consumo dessa substância. Tratase de um modelo misto porque incorpora, simultaneamente, elementos dos quadros antagônicos Jurídico-Moral, Biomédico e Política de Saúde.

Trata-se de um Discurso JurídicoMoral 'Humanizador' visto que incorpora 
elementos que integram o enquadramento Jurídico-Moral e se apropria de elementos que participam do modelo psicossocial de atenção aos usuários de substâncias psicoativas, travestindo-se, a nível superficial do discurso, de modelo de Política de Saúde.

Cabe resgatar que o quadro JurídicoMoral, investigado na etapa de análise das notícias, compreende o crack como problema em si e o seu uso como doença ${ }^{21}$, associa violência ao consumo e é centrado no uso de armas sofisticadas como instrumentos de coerção ${ }^{22,23}$, apresentando a internação compulsória como medida prioritária ${ }^{24}$.

O discurso correspondente ao enquadre Política de Saúde observado nas notícias, por sua vez, remete aos seguintes elementos: uso do crack como enfoque da rede de serviços de saúde; promoção da saúde, vida e cidadania; e a horizontalidade da atenção ${ }^{25}$.

Observa-se que a FD Jurídico-Moral 'Humanizadora' identificada nas entrevistas indica a presença de uma espécie de um sistema complexo de diagnose e de terapêutica próprios compartilhado entre os profissionais da USF. Utilizou-se o termo 'humanizadora' entre aspas porque se trata de uma formação discursiva que ideologicamente se pretende humanizadora, embora permaneça como subtipo do enquadre Jurídico-Moral: conquanto apresente um modelo de diagnose e terapêutica próprios, produz os mesmos efeitos de sentido, reproduzindo a dialética inclusão/exclusão.

É possível identificar que se trata de um sistema simbólico e ideológico de representação, à semelhança do conceito de racionalidade ${ }^{26}$. Trata-se de um sistema simbólico sobre os usuários e sobre a droga dotado de organização, constituído de um corpus doutrinário e de um sistema próprio de diagnose e de terapêutica que incorpora diferentes elementos compartilhados pelos quadros discursivos presentes na mídia.

Este corpus doutrinário compreende a droga em si como substância autônoma, maléfica e viva, dotada de força de vontade, responsável pelos descaminhos dos usuários doentes acometidos pelo vício, destituídos de força de vontade e vitimados pela droga ${ }^{11}$.

Quanto ao modelo de diagnose, observaram-se: a incorporação de condicionantes e determinantes psicológicos, emocionais e sociais ao lado de fatores fisiológicos na explicação etiológica; e a escalada das drogas e o crack como substância-estágio final da decadência físico-moral humana.

Um modelo de terapêutica que pressupõe: a 'humanização' da assistência ao usuário na dialética exclusão e inclusão ${ }^{27}$ por meio da rejeição à intervenção policial e da aceitação da repressão sanitária; o usuário como alvo passivo da intervenção psicossocial e religiosa, realizada pela conjugação de serviços públicos e privados; a rede como não substitutiva e a persistência da internação compulsória como retaguarda diante da falência do convencimento.

\section{Corpus doutrinário: a droga em si como substância autônoma dotada de força de vontade versus usuário como doente e destituído de vontade}

No que diz respeito aos efeitos discursivos relativos à compreensão da droga, para o Discurso Jurídico-Moral Humanizador, os profissionais de saúde assumem a droga como uma substância dotada de vontade e autonomia próprias, entidade viva e má, que se sobrepõe imperiosa à questionável força de vontade dos 'viciados' a ela submetida:

Com o uso prolongado, o 'distanciamento familiar, o distanciamento social, né, o isolamento social mesmo, problema de saúde, diminuição da capacidade cognitiva, ele pode ficar meio letárgico, acho que também questões de estrutura'... [...]. Como ele é fumado, a temperatura mais elevada que o nosso corpo causa problema no sistema respiratório superior, então eu acho que é isso. [...] O uso da droga, ele usou 'muita droga, muita droga, e tornou psiquiátrico'. Aí a gente foi estudar esse assunto e a gente chegou à conclusão de que ele já tinha uma 'doença psiquiátrica 
de base que tava lá, adormecida, quietinha no canto dela, e que o uso prolongado das drogas, o crack, a cocaína, fez com que desencadeasse essa patologia psicológica', o uso da droga também tem essa consequência né, ela pode exacerbar essas doenças psiquiátricas. (Taís).

Essa formação discursiva transita entre as noções de fraqueza física e fragilidade moral do sujeito ante o poder irresistível de uma droga imbuída de força de vontade. A fraqueza é física e moral porque é explicada com conceitos que remetem à fisiologia do usuário, assim como à sua condição de 'força psíquica': o usuário é definido como 'não evoluído', 'cabeça fraca', 'frágil de mente', sem 'força de vontade', 'mente ruim', 'alma vagando'. Trata-se de estrutura interna suscetível ao vício, fisiológica e psiquicamente comprometida, ou assim tornada pela repetição do uso. A droga emerge como fator disruptivo dos laços sociais, resultando na desagregação familiar. O seu uso é tido como doença psiquiátrica ou fuga de problemas pessoais ${ }^{\mathbf{2 8}, 29}$. O sujeito dependente torna-se indomesticável, suscetível aos seus impulsos indomáveis.

Eu acho 'que todo mundo vai morrer'. Acho que o fim é esse. Acontece, muitas vezes. Não só pelo uso, mas também pela situação que eles estão, né. De estar no meio da rua, e tal. Sempre acontece muitos casos de violência, assim, com os usuários. E eles 'param de comer, de se alimentar, só fumam, fumam, fumam o tempo todo, chega um momento que não aguenta mais, chega ao óbito', né. (Vanda).

Assim, o uso de crack aparece como condição análoga à loucura, a partir de termos como 'agressivo', ‘alteração', ‘agitado', 'zumbi', produzida pelo encontro do sujeito com a droga. O crack é considerado como 'resto' ou subproduto de uma outra droga, 'submassa da submassa da cocaína', com capacidade de interferir sobre o corpo e o espírito dos sujeitos e determinar sobre sua saúde e doença, bem como deliberar sobre a vida e a morte. A morte aparece como estágio final do consumo, e o tratamento compulsório é defendido diante da ineficiência do convencimento, alternativa ao fatalismo do 'vício'.

\section{Modelo de diagnose: a explicação etiológica do consumo}

O Discurso Jurídico-Moral Humanizador, não se restringindo aos elementos moralizadores do Discurso Jurídico-Moral, apresenta-se como novo subtipo deste, ao incorporar elementos dos enquadres Biomédico e Política de Saúde. Assim, adota na explicação etiológica do consumo do crack determinantes psicológicos e sociais, ao lado dos fatores fisiológicos.

Nesse sentido, entende-se que a determinação social do consumo envolve ausência de oportunidades, facilidade de acesso ao crack, pobreza, desemprego, influência de amigos e negligência familiar. São representados como fatores psicológicos e emocionais: tristeza, depressão, desânimo com a vida, conflitos familiares, trauma emocional, fuga da realidade. Por sua vez, a doença mental de base é entendida como fator fisiológico. São incluídas na explicação etiológica fatores morais e individuais como 'safadeza', 'fraqueza', escolha de vida. Dessa forma, adota-se a noção de múltipla determinação sem abandonar as explicações características do modelo Biomédico (predeterminação) e Jurídico-Moral (mau-caráter).

O sujeito da droga é definido pelo negativo, pela carência e pela falta de emprego, dinheiro, oportunidade, família estruturada, ou, quando possuidor de algo, é imbuído de tristeza, depressão, doença mental, 'safadeza' e 'coisa maligna'.

A explicação etiológica do consumo entre os profissionais incorpora a noção da escalada linear das drogas, em que aquelas como álcool e tabaco são definidas como 'portas de entrada' para outras como a maconha, considerada mais leve que a cocaína e, por último, o crack, considerada a mais nefasta. Trata-se 
de um processo ideológico que transforma o crack em fenômeno atemporal. Substância interpretada como estágio final da decadência humana, característico de 'moradores de rua', que permanecem em situação de degradação em logradouros públicos 'em decorrência do uso de crack', definindo a situação de rua como condição análoga ao último degrau da escalada das drogas: "O usuário de drogas não inicia pelo crack né, geralmente inicia pela maconha, pela cocaína, e por consequência ele chega até o crack". (Marluce). Perspectiva semelhante apresentada por outra profissional:

Porque do álcool, aí vai pra maconha, e depois da maconha, eu acho que já é entrada pro crack. Eu não falo cocaína porque ela é mais cara, e o crack tem facilidade, porque ele custa mais barato. (Irene).

Pessoas que já tinham uma certa dependência, do cigarro, do álcool, já eram pessoas que faziam uso há anos disso, que tiveram problemas com o alcoolismo, que foram expulsos de casa por algum motivo... trouxe algum problema... por ser uma droga barata, e as pessoas que são morador de rua disseminam muito isso. (Beto).

Para as profissionais de saúde, as maneiras de perceber o usuário e a droga resultam não apenas da formação técnica, mas também pelas experiências no lidar cotidiano com traficantes, usuários e mediadas pelos meios de comunicação.

Os meios de comunicação são tidos como veículos para obtenção de conhecimentos sobre o crack e sobre as pessoas que dele fazem uso, seja para corroborar os quadros discursivos Jurídico-Moral, seja para discordar deles, como Irene, que se questiona sobre os programas televisivos exibidos no horário de almoço que associam as drogas à violência. Em consonância com as críticas estabelecidas ao proibicionismo presentes no enquadre das Políticas Públicas, Irene problematiza a própria noção de 'droga' adotada pelo noticiário, que reduz a droga à marginalidade.

Taís se posiciona diante da maneira pela qual certos aspectos da realidade são considerados mais importantes pela mídia, construindo a 'epidemia do crack':

'Tem programas de reportagem que é demagogia' pura, que falam de pessoas que foram assassinadas, e tudo, acho que você sabe do que eu tô falando, dos 'programas de reportagem que passam meio-dia', e... em momento nenhum diz assim, o que foi feito pra que ele não chegasse a ser assassinado, que saísse dessa vida, ai é éćcil... álcool é droga, cigarro é droga, e tudo que vicia é droga. Chocolate vicia. Então. Às vezes a pessoa já passou por problema de se alcoolizar, várias vezes e tudo, só porque diz a sociedade que é licita, mas... (Irene).

Agora com relação à mídia, eu acho que é isso mesmo, tanto na televisão, no jornal, revista e internet, eles tentam mesmo problematizar uma coisa que já é grande, já é crítica, mas eles tentam de certa forma mostrar maior, mostrar sempre mais. Fazer com que a coisa se torne maior. Quando teve aquela invasão da cracolândia, que invadiu pra acabar com a cracolândia, a mídia pegou em cima e mostrou de forma arbitrária, agressiva, a maneira com que foi feita a invasão... às vezes a mídia acaba não ajudando. (Taís).

A recepção não se reduz à decodificação da mensagem, mas é processo de produção das formas simbólicas. A recepção é ato interpretativo, em que interagem os bens simbólicos com as diferentes trajetórias dos sujeitos ${ }^{\mathbf{1 4}}$.

Os sentidos produzidos midiaticamente circulam na sociedade entre pessoas, grupos e instituições, influenciando a cultura ${ }^{14,15}$. Os resultados apontam que os enquadramentos presentes nas notícias veiculadas sobre o programa Crack, é Possível Vencer são interpretados de modo singular, produzindo um modelo misto de compreensão do fenômeno das drogas, formação discursiva que chamamos de Discurso Jurídico-Moral 
Humanizador. Por essa razão, observa-se que não é possível pensar os modos de diagnose e de terapêutica dos usuários de crack adotados pelos profissionais de forma dissociada dos quadros discursivos da mídia.

\section{Modelo de tratamento: o usuário como alvo da intervenção e a inter- nação compulsória diante da falência do convencimento}

A interpretação dos dados indica um modelo de terapêutica amparado em três aspectos: a 'humanização' da assistência ao usuário na dialética exclusão e inclusão por meio da rejeição à intervenção policial e da aceitação da repressão sanitária; o usuário como alvo passivo da intervenção, realizada pela conjugação de serviços públicos e de instituições privadas financiadas pelo poder público; a rede como ineficaz e não substitutiva, resolvida pela internação involuntária, retaguarda dos serviços assistenciais diante da falência do convencimento do usuário ao tratamento.

Os discursos dos profissionais apontam para a rejeição à intervenção policial e aos instrumentos de repressão como o encarceramento, o spray de pimenta e a arma de choque, em detrimento de um novo 'humanismo', produzindo sentidos que corroboram a adoção de mecanismos assemelhados a uma nova coerção, a repressão sanitária:

Eu acho que 'quando tá numa fase que não tem jeito eu acho que isso tem que acontecer a internação involuntária. Até pro bem dele'. Porque ele pode causar várias alterações no sistema nervoso central, então tem pacientes que ficam em surto mesmo, completamente, e que tipo precisa daquilo, mesmo não querendo, a família naquele momento tem que se posicionar e fazer o que é melhor pra ele. (Maiara).

Tem essa frase aqui na notícia, 'a internação compulsória é protetora da vida e reprodutora da cidadania', que é o que eu falei no início né, 'a pessoa fica vulnerável em situação de extrema vulnerabilidade, e você vai proteger a vida dela', então naquele momento, às vezes, nós como responsáveis né... [...] Eu falei lá pra uma paciente que estava com uma tosse que não era bem verídica, né, que se você continuar tossindo assim, durante meia hora seu pulmão vai fadigar e seu músculo vai parar de respirar. Então, eu como profissional não posso permitir isso. Se você continuar tossindo assim, por mais que você diga que tem controle ou não, eu vou precisar fazer algumas medidas pra poder resolver isso, né... intubação... pra poder proteger o seu pulmão, porque você não vai poder continuar tossindo assim. Aí ela: 'eu mando em mim!' aí eu falei não, 'no momento em que você está sob meus cuidados, quem é responsável sou eu e o profissional médico'. Da mesma forma que é um paciente, tá vulnerável, então a partir do momento que eu trabalho com isso, 'eu tenho a responsabilidade sobre aquele paciente, então a decisão ali também parte por mim, a depender do estado crítico que ele esteja'. Então, realmente 'a internação compulsória é protetora'. (Taís).

A internação compulsória não é rejeitada, mas assumida como possibilidade diante da ineficiência dos serviços públicos. O sujeito destituído de vontade pela droga é submetido aos desígnios e ao poderio dos profissionais de saúde, responsáveis absolutos pela vida do 'paciente'. O uso da droga coincide com a situação de risco e desproteção, que exige do profissional 'se posicionar e decidir o que é melhor para ele', sendo ‘o melhor' a internação involuntária. Defende-se uma nova internação, mais 'humanizada', em que o acompanhamento é realizado não em manicômios, mas em hospitais 'repaginados'.

Por essa razão, esta formação discursiva nega a repressão policial e a violência carcerária, denunciando a ineficiência da coerção estatal, para ressituar a repressão na gestão dos corpos e dos afetos dos usuários por meio das práticas assistenciais desenvolvidas pelos serviços de saúde:

Eu acho que primeiro a família, porque a família é a base de tudo. Mesmo sendo a família desorientada [...]. E vir com a 'ajuda psicológica, o 
posto de saúde', porque envolve também outros problemas. 'A polícia não, porque eu diria que a polícia... não sei, ia ser mais agressivo'. Tem que ser a parte mesmo mais da familia, trabalhar a família, porque a família não vem a nós mesmo sem fazer uso da droga porque adoece, adoece muito, então... tem que buscar mesmo ajuda psicológica pra trabalhar a familia e trabalhar essa pessoa. Porque se a pessoa adoece, adoece a família toda... muito triste. (Julinda).

Mas... 'essa arma de choque aqui, eu acho muito pesado'. Eu acho que eles agiam com muita... eu acho que eles [os policiais] são muito ignorantes...eles tão tentando convencer de que é normal, usar arma de choque, pra lidar com os usuários de crack, que são 'viciados', que são 'violentos', que isso e que aquilo... ainda critica aqui, que alguns especialistas criticam que o foco tem que ser maior na saúde... isso daqui pra mim só deveria ser naquele caso... 'naquele último caso, vamos supor, quero internar ele, o usuário não colabora de jeito nenhum, tá superdrogado lá, superagressivo, poderia até pensar nisso, mas também acho uma medida muito brusca'. Concordo nisso aqui, 'focar mais na saúde'. (Vanda).

Essa nova repressão sanitária, na qual as pessoas que fazem uso do crack se tornam alvo, reproduz o que Sawaia ${ }^{27}$ chamou de dialética da inclusão/exclusão. Consiste em um processo dialético porque se trata de elementos indissociáveis, não sendo possível pensar os modos de inclusão disponíveis aos usuários de crack nos serviços dissociados dos aparatos institucionais e simbólicos que objetivam a gestão dos seus corpos desviantes.

A exclusão é dotada de uma ambiguidade constitutiva, responsável pela coesão social: o Discurso Jurídico-Moral Humanizador produz efeitos que garantem a continuidade desse processo dialético. A inclusão dos usuários de crack nos serviços e nas práticas assistenciais é evidenciada pelo seu caráter ilusório, pois para incluir é preciso excluir, assim como o seu contrário ${ }^{27}$.

Lancetti $^{30}$ já indicava a fragilidade da redução do problema dos manicômios à humanização, por meio da eliminação da violência adicional. A negação da instituição não significa a simples derrubada dos manicômios, mas a recusa da racionalidade terapêutica que objetiva a cura e que reduz as questões sociais que envolvem as pessoas que usam substâncias à noção de 'doença' (no modelo clínico) ou de 'conflito' (no modelo psicológico) ${ }^{31}$.

Essa negação epistêmica restituiu o saber da experiência por meio da reorientação da 'doença do sujeito' à 'existência-sofrimento do doente'31, por intermédio da ruptura de antigos dispositivos que ainda permanecem como parte do conjunto institucional referido à doença ou à periculosidade, sustentado pelos aparatos científicos, legislativos, administrativos e culturais ${ }^{30,31}$.

É por meio de práticas ditas 'humanitárias' que se revela o processo de cronificação. Os usuários são cronificados por um ambiente social refratário à inclusão e por condições socioculturais adversas marcadas por práticas discriminatórias e pela negação de seus direitos ${ }^{32}$. Essas práticas ocultam em seu interior 'desejos de manicômio', anseios por subjugação e opressão estabelecidos na relação de poder entre profissionais e usuários. Tratase de exercer a ruptura desse dispositivo que ainda permanece referido à violência ${ }^{33}$.

Diante da falência do convencimento, restaria aos profissionais conduzir os usuários aos rigores das práticas eugênicas: inclusão na rede de serviços assistencialistas e religiosos ou em instituições psiquiátricas 'humanizadas' orientadas pela contenção, pela exclusão do convívio e pela obediência ao princípio inviolável da abstinência.

\section{Considerações finais}

O estudo possibilitou identificar os modos com que a mídia afeta discursos e práticas assistenciais de uma ESF na atenção às pessoas que usam drogas. Alguns dos enquadramentos da mídia observados nas 
notícias sobre o programa Crack, é Possível Vencer, quais sejam, os quadros JurídicoMoral, Política de Saúde, Biomédico, foram percebidos nos discursos dos profissionais por meio da produção de um modelo misto, identificado como Discurso Jurídico-Moral Humanizador, formação ideológica que, sob a aparência do discurso humanizador, integrando elementos do quadro Política de Saúde na explicação etiológica do uso crack, produz os mesmos efeitos de sentido que o quadro Jurídico-Moral.

Ao mesmo tempo que se recusa a repressão policial e a adoção de aparatos visíveis de coerção, adere-se aos dispositivos institucionais nem sempre visíveis de violência sanitária, como a internação compulsória, legitimada pelo passivo reconhecimento da desarticulação da rede de atenção psicossocial e pelo corpus biomédico compartilhado pelos profissionais, que define o usuário como indivíduo avolitivo, dominado pela substância autônoma.

\section{Referências}

1. Brasil. Ministério da Justiça. Crack, é possível vencer [internet]. Brasília, DF: Ministério da Justiça; [data desconhecida] [acesso em 2017 mar 16]. Disponível em: http://www.justica.gov.br/sua-seguranca/seguranca-publica/programas-1/crack-e-possivel-vencer.

2. Brasil. Presidência da República. Plano integrado de enfrentamento ao crack e outras drogas [internet]. Brasília, DF; 2014 [acesso em 2017 mar 17]. Disponível em: http://www2.planalto.gov.br/acompanhe-o-planalto/caderno-destaques/marco-2012/ plano-integrado-de-enfrentamento-ao-crack-e-ou-
As práticas discursivas podem corroborar a desassistência aos usuários de crack na USF e legitimar vazios assistenciais, cada vez mais preenchidos por instituições amparadas em um modelo de atenção manicomial, mais humanizado e não menos perverso, que sobrevive se sustentando por meio de financiamento público, ajustando-se às fragilidades na implementação da reforma psiquiátrica e sanitária no Brasil.

\section{Colaboradores}

Todos os autores contribuíram para a concepção, o planejamento, a análise e a interpretação dos dados; para a elaboração do texto e revisão crítica do conteúdo; e participaram da aprovação da versão final do manuscrito tras-drogas.

3. Alves VS. Modelos de atenção à saúde de usuários de álcool e outras drogas: discursos políticos, saberes e práticas. Cad. Saúde Pública. [internet]. 2009 [acesso em 2017 mar 14]; 25(11):2309-2319. Disponível em: http://www.scielo.br/scielo.php?script=sci arttext\&pid=S0102-311X2009001100002\&lng=en\& nrm=iso\&tlng=pt.

4. Brasil. Lei $\mathrm{n}^{\circ}$ 10.216, de 6 de abril de 2001. Dispõe sobre a proteção e os direitos das pessoas portadoras de transtornos mentais e redireciona o mode- 
lo assistencial em saúde mental. Diário Oficial da União. 6 abr 2001.

5. Brasil. Ministério da Saúde. Coordenação Nacional de DST/Aids. A Política do Ministério da Saúde para atenção integral a usuários de álcool e outras drogas. Brasília, DF: Ministério da Saúde; 2003.

6. Brasil. Lei $\mathrm{n}^{\circ} 11.343$, de 23 de agosto de 2006. Institui o Sistema Nacional de Políticas Públicas sobre Drogas - Sisnad; prescreve medidas para prevenção do uso indevido, atenção e reinserção social de usuários e dependentes de drogas; estabelece normas para repressão à produção não autorizada e ao tráfico ilícito de drogas; define crimes e dá outras providências. Diário Oficial da União. 23 ago 2006.

7. Brasil. Decreto no 7.179, de 20 de maio de 2010. Institui o Plano Integrado de Enfrentamento ao Crack e outras drogas, cria o seu comitê gestor, e dá outras providências. Diário Oficial da União. 21 maio 2010.

8. Machado LV, Boarini ML. Políticas sobre drogas no Brasil: a estratégia de redução de danos. Psicol. Ciênc. Prof. [internet]. 2013 [acesso em 2018 abr 4]; 33(3):580-595. Disponível em: http:// www.scielo.br/scielo.php?script=sci_arttext\&pid $=$ S1414-98932013000300006.

9. Souza J, Fioratti RC, Macedo MM, et al. Brazilian Public Policies on Drugs: An Analysis Considering the Aspects of Assistance, Prevention, and Supply Control. J Addict Nurs. 2018; 29(1):50-56.

10. Costa PH, Ronzani TM, Colugnati FAB. No papel é bonito, mas na prática: análise sobre a rede de atenção aos usuários de drogas nas políticas e instrumentos normativos da área. Saúde Soc. [internet]. 2017 [acesso em 2018 abr 4]; 26(3):738-750. Disponível em: https://doi.org/10.1590/S010412902017170188.

11. Cunda MF, Silva RAN. O crack em um cenário empedrado: articulações entre o discurso jurídico, médico e midiático. Psicol. Soc. [internet]. 2014 [acesso em 2017 mar 12]: 26(esp):245-255. Disponível em: http://www.scielo.br/pdf/psoc/v26nspe/25.pdf.
12. Toledo LG, Góngora A, Bastos FIPM. À margem: uso de crack, desvio, criminalização e exclusão social - uma revisão narrativa. Ciênc. Saúde Colet. [internet]. 2017 [acesso em 2018 abr 7] 22(1):3142. Disponível em: https://doi.org/10.1590/141381232017221.02852016 .

13. Moreira MR, Fernandes FMB, Ribeiro JM, et al. Uma revisão da produção científica brasileira sobre o crack - contribuições para a agenda política. Ciênc. Saúde Colet. [internet]. 2015 [acesso em 2017 mar 14]; 20(4):1047-1062. Disponível em: http:// www.scielo.br/pdf/csc/v20n4/pt_1413-8123csc-20-04-01047.pdf.

14. Hjarvard S. Midiatização: teorizando a mídia como agente de mudança social e cultural. Matrizes [internet]. 2012 [acesso em $2016 \mathrm{dez}$ 12]; 8(2):53-91. Disponível em: http://www.periodicos.usp.br/matrizes/article/view/38327/41182.

15. Fausto Neto A. Fragmentos de uma «analítica» da midiatização. Matrizes [internet]. 2008 [acesso em 2016 dez 11]; 1(2):89-105. Disponível em: https:// www.revistas.usp.br/matrizes/article/viewFile/38194/40938.

16. Barros LM. Recepção, mediação e mediatização: conexão entre teorias europeias e latino-americanas. In: Janotti Júnior J, Mattos MA, Jacks N, organizadores. Mediação \& midiatização. Salvador: Edufba; 2012. p. 79-105.

17. Gonçalves T. A abordagem do enquadramento nos estudos do jornalismo. Caleidoscópio: Rev. Comun. Cult. [internet]. 2011 [acesso em 2017 mar 18]; S.1(5/6):157-167. Disponível em: http://recil.ulusofona.pt/bitstream/handle/10437/2605/A\%20Abordagem $\% 20$ do\%20Enquadramento\%20nos\%20Estudos\%20do\%20Jornalismo.pdf?sequence=1.

18. Carvalho CA. Sobre limites e possibilidades do conceito de enquadramento jornalístico. Contemporânea Rev. Comun. Cult. [internet]. 2010 [acesso em 2016 nov 26]; 7(2):1-15. Disponível em: https://portalseer.ufba.br/index.php/contemporaneaposcom/ article/view/3701/2885. 
19. Orlandi EP. Análise de discurso: princípios e procedimentos. 6. ed. Campinas: Pontes; 2005.

20. Bravo OA. Discurso sobre drogas nas instituições públicas do DF. Temas psicol. [internet]. 2002 [acesso em 2017 fev 18]; 10(1):39-51. Disponível em: http://pepsic.bvsalud.org/scielo.php?script=sci arttext\&pid=S1413-389X2002000100004.

21. Cheibub WB. Práticas disciplinares e uso de drogas: a gestão dos ilegalismos na cena contemporânea. Psicol., Ciênc. Prof. [internet]. 2006 [acesso em 2016 dez 12]; 26(4):548-557. Disponível em: http://www. scielo.br/scielo.php?script=sci_arttext\&pid=S1414$-98932006000400003 \& \operatorname{lng}=$ en $\&$ nrm=iso\&tlng=pt.

22. Ronzani TM, Fernandes AGB, Gebara CFP, et al. Mídia e drogas: análise documental da mídia escrita brasileira sobre o tema entre 1999 e 2003. Ciênc. Saúde Colet. [internet]. 2009 [acesso em 2017 mar 18]; 14(5):1751-1761. Disponível em: http://www. scielo.br/scielo.php?script=sci_arttext\&pid=S1413$-81232009000500016 \& \operatorname{lng}=$ en\&nrm=iso\&tlng=pt.

23. Noto AR, Baptista MC, Faria ST, et al. Drogas e saúde na imprensa brasileira: uma análise de artigos publicados em jornais e revistas. Cad. Saúde Pública [internet]. 2003 [acesso em 2016 dez 12]; 19(1):6979. Disponível em: http://www.scielo.br/scielo. php?script=sci_arttext\&pid=S0102-311X20030001 00008\&lng=en\&nrm=iso\&tlng=pt.

24. Wurdig KK, Motta RF. Representações midiáticas da internação compulsória de usuários de drogas. Temas psicol. [internet]. 2014 [acesso em $2016 \mathrm{dez}$ 12]; 22(2):433-444. Disponível em: http://pepsic.bvsalud.org/scielo.php?script=sci_arttext\&pid=S1413-389X2014000200014.

25. Pitta AMF, organizadora. Reabilitação psicossocial no Brasil. 4. ed. São Paulo: Hucitec; 2016.

26. Luz MT. Novos saberes e práticas em saúde coletiva: estudos sobre racionalidades médicas e atividades corporais. 3. ed. São Paulo: Hucitec; 2012.
27. Sawaia B. O sofrimento ético-político como categoria de análise da dialética exclusão/inclusão. In: Sawaia B, organizadora. As artimanhas da exclusão: análise psicossocial e ética da desigualdade social. 2. ed. Petrópolis: Vozes; 2001. p. 97-118.

28. Romanini M, Roso A. Mídia e crack: promovendo saúde ou reforçando relações de dominação? Psicol., Ciênc. Prof. [internet]. 2012 [acesso em 2017 mar 18]; 32(1):82-97. Disponível em: http:// www.scielo.br/scielo.php?script=sci_arttext\&pid $=$ S1414-98932012000100007.

29. Romanini M, Roso A. Mídia, ideologia e cocaína (crack): produzindo 'refugo humano'. Psico-USF [internet]. 2013 [acesso em 2017 mar 18]; 18(3):373382. Disponível em: http://www.scielo.br/pdf/ pusf/v18n3/a04v18n3.pdf.

30. Lancetti A. Notas sobre humanização e biopoder. Interface-comun., saúde, educ. [internet]. 2009 [acesso em 2016 dez 12]; 13(1):797-799. Disponível em: http://www.scielo.br/scielo.php?script=sci_art text\&pid=S1414-32832009000500033.

31. Rotelli F. A instituição inventada. In: Rotelli F, Leonardis O, Mauri D, organizadores. Desinstitucionalização. São Paulo: Hucitec; 2001. p. 89-100.

32. Dimenstein M. O desafio da política de saúde mental: a (re)inserção social dos portadores de transtornos mentais. Mental [internet]. 2006 [acesso em 2017 mar 12]; 4(6):69-82. Disponível em: http://pepsic.bvsalud.org/scielo.php?script=sci_arttext\&pid $=$ S1679-44272006000100007.

33. Machado LD, Lavrador MCC. Subjetividade e loucura. Texturas da psicologia: subjetividade e política no contemporâneo. São Paulo: Casa do Psicólogo; 2002.

Recebido em 15/11/2017

Aprovado em 08/04/2018

Conflito de interesses: inexistente

Suporte financeiro: não houve 